\title{
Diagnostic Performance of Digital Radiograph and Low-Dose Computed Tomography for the Diagnosis of Fishbone Retention in the Oropharynx
}

\author{
Jirapa Chansangrat ${ }^{10}$ \\ ${ }^{1}$ School of Radiology, Medical Institute, Suranaree University of \\ Technology, Nakhon Ratchasima, Thailand
}

Int Arch Otorhinolaryngol 2022;26(3):e401-e406.
Address for correspondence Jirapa Chansangrat, M.D., Radiologist, Suranaree University of Technology, 111 Mahawittayalai road, Nakhon Ratchasima 30000, Thailand (e-mail: Jirapa@sut.ac.th).

\begin{abstract}
Keywords

- fishbone

- oropharyngeal

- esophageal

- foreign body

- diagnostic performance

- CT

- digital radiograph

Introduction Fishbone foreign body retention is one of the most common problem with various clinical manifestations from asymptomatic, abscess formation, and perforation to mediastinitis with subsequence morbidity and mortality. Accurately identifying the location of the fishbone leads to precise removal, which, in turn, prevents serious consequences. Digital radiographs have been widely used for diagnosis, but many studies show poor sensitivity.

Object The present study was designed to compare the diagnostic performances of digital radiograph and low-dose computed tomography (CT) for fishbone retention and to demonstrate the radiation dose of the two modalities.

Methods We collected 2 pieces of fishbone from each of the 15 species commonly eaten in Southeast Asia. We embedded each fishbone in a fresh pig's neck, then subjected the pig's neck to lateral soft tissue neck digital radiograph. The locations to embed included tonsil, base of tongue, and upper esophagus. Then, we subjected the same specimen to a CT scan. Two experienced radiologists interpreted each image.

Results Visibility in the digital radiograph group was $13 \%$, and in CT images group, it was $87 \%$ regardless of the locations. The average radiation dose from digital radiographs was $0.4 \mathrm{mGy}$ (radiation dose field), while from CT images it was $8.6 \mathrm{mGy}$ (CT dose index).

Conclusion Most of the common fishbones in Southeast Asia could not be visualized by digital radiograph when embedded in the neck. Computed tomography scans demonstrated better diagnostic performance of fishbone retention compared to digital radiographs, regardless of the embedded location.
\end{abstract}

\section{Introduction}

There are variations in the causes of food-borne foreign body disease among geographic regions and cultures. Oropharyngeal fishbone retention is one of the most common cause, particularly in the Asian culture and in coastal areas (42$76 \%)^{1,2}$

The condition has spectrums of clinical manifestation from mild to fatal. The symptoms consist of foreign body sensation, irritation, sore throat, dysphagia, odynophagia, received

March 5, 2021

accepted after revision

August 4, 2021

published online

November 8, 2021
DOI https://doi.org/

10.1055/s-0041-1735567.

ISSN 1809-9777.

\footnotetext{
(c) 2021. Fundação Otorrinolaringologia. All rights reserved.

This is an open access article published by Thieme under the terms of the Creative Commons Attribution-NonDerivative-NonCommercial-License, permitting copying and reproduction so long as the original work is given appropriate credit. Contents may not be used for commercial purposes, or adapted, remixed, transformed or built upon. (https://creativecommons.org/ licenses/by-nc-nd/4.0/)

Thieme Revinter Publicações Ltda., Rua do Matoso 170, Rio de Janeiro, RJ, CEP 20270-135, Brazil
} 
abscess, mediastinitis, and perforation. ${ }^{3-5}$ Approximately 80 to $90 \%$ of ingested foreign bodies are passed spontaneously. ${ }^{3}$ About 10 to $20 \%$ require intervention for removal. ${ }^{5}$ Frequent lodging sites in the oropharynx are the tonsils, base of the tongue, valleculae, and pyriform recesses. The tonsils are the most common site, followed by the base of the tongue. The most common location in the esophagus is the upper esophageal sphincter. ${ }^{1,2}$

There is still no clear algorithm for the diagnosis and management of fishbone retention. ${ }^{6}$

In Thailand, digital radiographs are still the imaging modality of choice for initial evaluation in the treatment of fishbone retention. However, many studies have revealed poor sensitivity and specificity of this imaging modality. ${ }^{1,2,7-10}$ And the fact that the bones of different species of fish vary in degree of opacification under plain film leads to doubt about the usefulness of this modality. Computed tomography (CT) has emerged as an optional imaging modality to evaluate foreign body retention. As technology progressed, there is now better
CT imaging quality, and it can produce lower radiation dose $\mathrm{e}^{11}$. The present study intended to evaluate the diagnostic performance of plain films compared to CT scans, and the added value of CT scans to plain films.

\section{Methods}

We collected two pieces of fishbone from each of the 15 species commonly eaten in Southeast Asia, particularly in Thailand (-Table 1). Each piece measured approximately $2 \mathrm{~cm}$. A radiograph of all 30 pieces of fishbone was taken (-Fig. $\mathbf{1}$ ).

Next, we embedded each fishbone in a fresh pig's neck, whose neck circumference and laryngeal framework was similar to that of an adult human. ${ }^{12}$ For tonsils and the base of the tongue, we used an alligator forceps to hold the fishbone and embedded it under direct laryngoscope. For the esophageal location, we used the longer alligator forceps, under direct laryngoscope and with fluoroscopic guidance.

(-Fig. 2)

Table 1 Visibility of each fishbone species by imaging modality and embedded site

\begin{tabular}{|c|c|c|c|c|c|c|c|}
\hline \multirow[b]{2}{*}{ Number } & \multirow[b]{2}{*}{ Name } & \multicolumn{3}{|c|}{ Digital radiograph } & \multicolumn{3}{|c|}{ CT scan } \\
\hline & & Tonsil & $\begin{array}{l}\text { Base of } \\
\text { tongue }\end{array}$ & $\begin{array}{l}\text { Upper } \\
\text { esophagus }\end{array}$ & Tonsil & $\begin{array}{l}\text { Base of } \\
\text { tongue }\end{array}$ & $\begin{array}{l}\text { Upper } \\
\text { esophagus }\end{array}$ \\
\hline 1 & $\begin{array}{l}\text { Common Silver Barb } \\
\text { (B. gonionotus) }\end{array}$ & 0 & 0 & 0 & 1 & 1 & 1 \\
\hline 2 & $\begin{array}{l}\text { Nile Tilapia } \\
\text { (O. niloticus) }\end{array}$ & 0 & 0 & 0 & 1 & 1 & 1 \\
\hline 3 & $\begin{array}{l}\text { Red Tilapia } \\
\text { (O. niloticus) }\end{array}$ & 0 & 0 & 0 & 1 & 1 & 1 \\
\hline 4 & $\begin{array}{l}\text { Tongue Sole } \\
\text { (C. macrolepidotus) }\end{array}$ & 0 & 0 & 0 & 1 & 1 & 1 \\
\hline 5 & $\begin{array}{l}\text { Short-bodied Mackerel } \\
\text { (R. brachysoma) }\end{array}$ & 0 & 0 & 0 & 1 & 1 & 1 \\
\hline 6 & $\begin{array}{l}\text { Catfish } \\
\text { (C. macrocephalus) }\end{array}$ & 1 & 1 & 1 & 1 & 1 & 1 \\
\hline 7 & $\begin{array}{l}\text { Black Kingfish } \\
\text { (R. canadum) }\end{array}$ & 0 & 0 & 0 & 1 & 1 & 1 \\
\hline 8 & $\begin{array}{l}\text { Asian Seabass } \\
\text { (L. calcarifer) }\end{array}$ & 0 & 1 & 1 & 1 & 1 & 1 \\
\hline 9 & $\begin{array}{l}\text { Salmon } \\
\text { (S. salar) }\end{array}$ & 0 & 0 & 0 & 1 & 1 & 1 \\
\hline 10 & $\begin{array}{l}\text { Areolated Grouper } \\
\text { (E. areolatus) }\end{array}$ & 0 & 0 & 0 & 1 & 1 & 1 \\
\hline 11 & $\begin{array}{l}\text { Longtail Tuna } \\
\text { (S. japonicas) }\end{array}$ & 0 & 0 & 0 & 0 & 0 & 0 \\
\hline 12 & $\begin{array}{l}\text { Silver Pomfret } \\
\text { (O. ruber) }\end{array}$ & 0 & 0 & 0 & 0 & 0 & 0 \\
\hline 13 & $\begin{array}{l}\text { Snakeskin Gourami } \\
\text { (T. pectoralis) }\end{array}$ & 0 & 0 & 0 & 1 & 1 & 1 \\
\hline 14 & $\begin{array}{l}\text { Spanish Mackerel } \\
\text { (S. commersoni) }\end{array}$ & 0 & 0 & 0 & 1 & 1 & 1 \\
\hline 15 & $\begin{array}{l}\text { Sablefish } \\
\text { (A. fimbria) }\end{array}$ & 0 & 1 & 0 & 1 & 1 & 1 \\
\hline
\end{tabular}

Visibility $0=$ invisibility group, $1=$ visibility group.

Digital radiograph. 


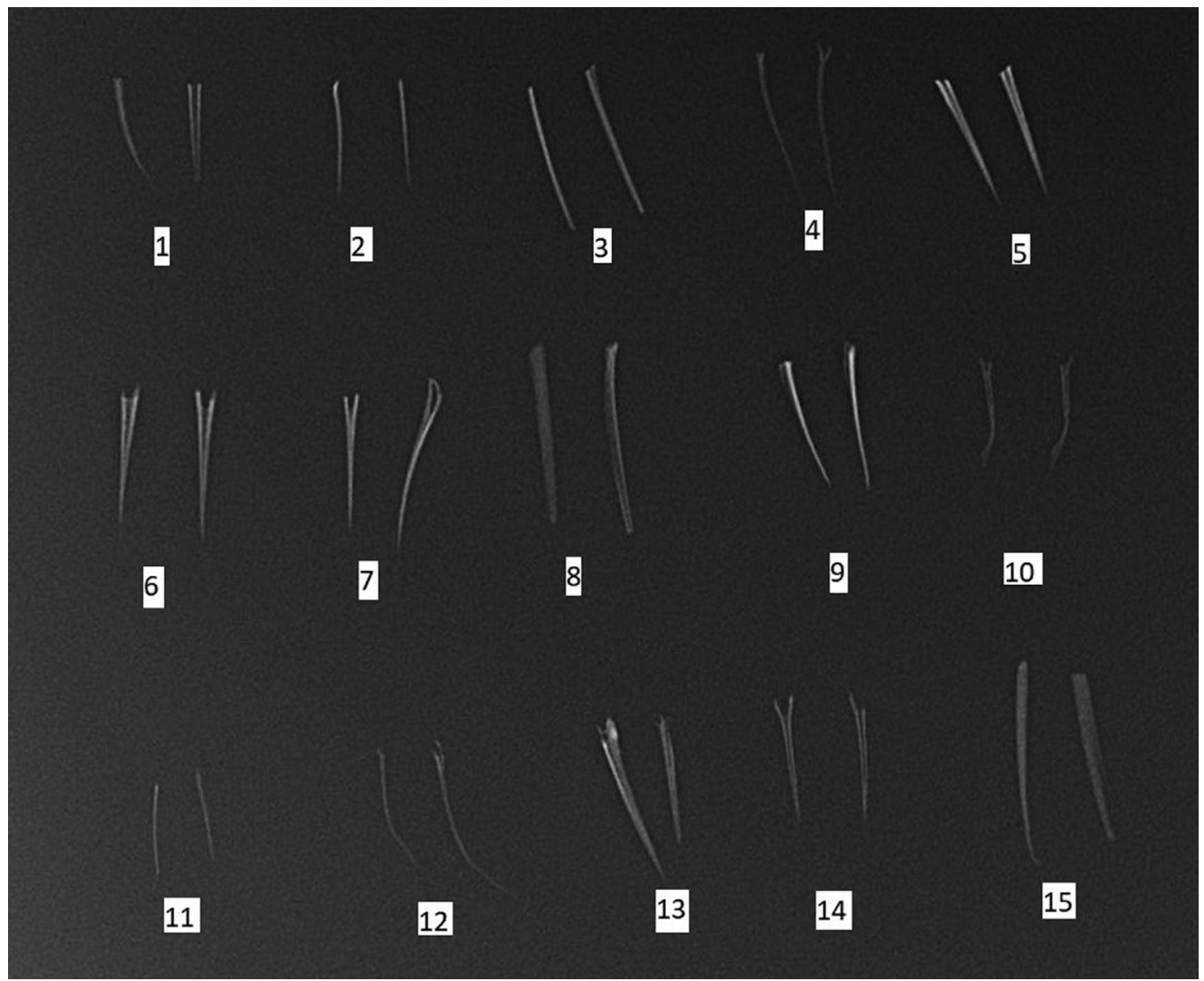

Fig. 1 Radiograph of 30 fishbones 1 =Common Silver Barb; 2 =Nile Tilapia; $3=$ Red Tilapia; $4=$ Tongue Sole; $5=$ Short-bodied Mackerel; $6=$ Catfish; $7=$ Black Kingfish; $8=$ Asian Seabass; $9=$ Salmon; $10=$ Areolated Grouper; $11=$ Longtail Tuna; $12=$ Silver Pomfret; $13=$ Snakeskin Gourami; 14 =Spanish Mackerel; 15 = Sablefish

We subjected the pig's neck to lateral soft tissue neck digital radiograph, with $318 \mathrm{~mA}, 70 \mathrm{kVp}$, using a GE Discovery XR656, model AL01C II (GE Healthcare, Chicago, IL, USA). The locations used include the tonsil, base of the tongue, and the upper esophagus. Scout films of the pig's neck were also obtained as control images.

Then, we subjected the same specimen to a CT scan, using Optima CT 660 (GE Healthcare), with standard plain CT protocol of the neck. The images were obtained and recorded by codes. Two experienced radiologists interpreted each

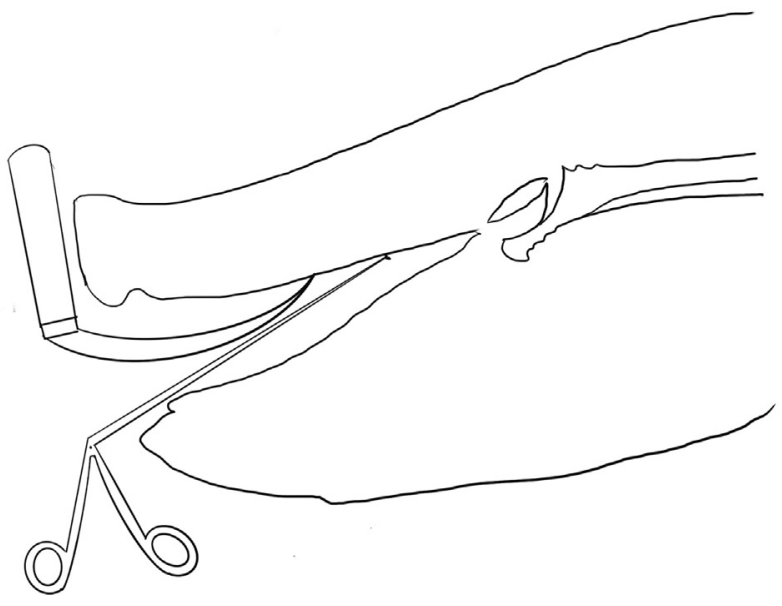

Fig. 2 Demonstrate method of embedding fishbones in the pig neck. image as "visualized" or "not visualized". Whenever there was difference in the interpretation, the two radiologists got together to find a consensus.

We defined the diagnostic performance of each imaging modality per different location using nonparametric receiver operating characteristics (ROC) curve analysis with Bamber and Hanley confidence intervals for the area under the ROC curve. To evaluate the additional benefit of CT images over digital radiographs, we also analyzed the added value of the ROC curve following each location where the fishbone was embedded.

\section{Result}

The visibility of the digital radiograph and CT images of the bone of each fish species is shown in table 1. Two pieces of fishbone from each species provided the same visibility results in both digital radiograph and CT images.

Visibility in the digital radiograph group was $13 \%$, and, in the CT images group, it was $87 \%$, regardless of the locations.

The average radiation dose from digital radiographs was $0.4 \mathrm{mGy}$ (radiation dose field), while from CT images it was $8.6 \mathrm{mGy}$ (CT dose index).

The accuracy of digital radiographs for the diagnosis of fishbone foreign bodies ranged from 53.3 to $58.3 \%$, with lodging site in the upper esophagus showing the highest accuracy and lodging site in the tonsils showing the poorest diagnostic performance (-Table 2 ). 
Table 2 Sensitivity, specificity, and accuracy with confidence intervals from digital radiographs in diagnosis of each site of fishbone retention

\begin{tabular}{|l|l|l|l|l|}
\hline Site & Sensitivity & Specificity & Accuracy & $95 \% \mathrm{Cl}$ \\
\hline Tonsil & $13.3 \%$ & $93.3 \%$ & $53.3 \%$ & $045-0.61$ \\
\hline $\begin{array}{l}\text { Base of } \\
\text { tongue }\end{array}$ & $20.0 \%$ & $93.3 \%$ & $56.7 \%$ & $0.48-0.65$ \\
\hline $\begin{array}{l}\text { Upper } \\
\text { esophagus }\end{array}$ & $20.0 \%$ & $96.7 \%$ & $58.3 \%$ & $0.50-0.66$ \\
\hline
\end{tabular}

Table 3 Sensitivity, specificity, and accuracy with confidence intervals from computed tomography in diagnosis of each site of fishbone retention

\begin{tabular}{|l|l|l|l|l|l|}
\hline Site & Sensitivity & Specificity & Accuracy & $95 \% \mathrm{Cl}$ & $\begin{array}{l}\text { Compare } \\
\text { added } \\
\text { value } \\
\text { ROC }\end{array}$ \\
\hline Tonsil & $93.3 \%$ & $100 \%$ & $96.7 \%$ & $0.92-1.00$ & $P<0.001$ \\
\hline $\begin{array}{l}\text { Base of } \\
\text { tongue }\end{array}$ & $93.3 \%$ & $100 \%$ & $96.7 \%$ & $0.92-1.00$ & $P<0.001$ \\
\hline $\begin{array}{l}\text { Upper } \\
\text { esophagus }\end{array}$ & $93.3 \%$ & $100 \%$ & $96.7 \%$ & $0.92-1.00$ & $P<0.001$ \\
\hline
\end{tabular}

Abbreviations: $\mathrm{Cl}$, confidence interval; $\mathrm{ROC}$, receiver operator characteristics.

Computed tomography images demonstrated accuracy for the diagnosis of fishbone retention of $96.7 \%$ in all locations. The added diagnostic value of CT scan over digital radiographs was statistically significant in all lodging sites (-Table 3). Diagnostic performance of digital radiographs and CT images according to the lodging site is shown in ROC curves (-Fig. $\mathbf{3}$ )

\section{Discussion}

Digital radiograph has been widely used due to its availability and reasonable cost. In the past, the use of CT scans for bony foreign body identification was not common,

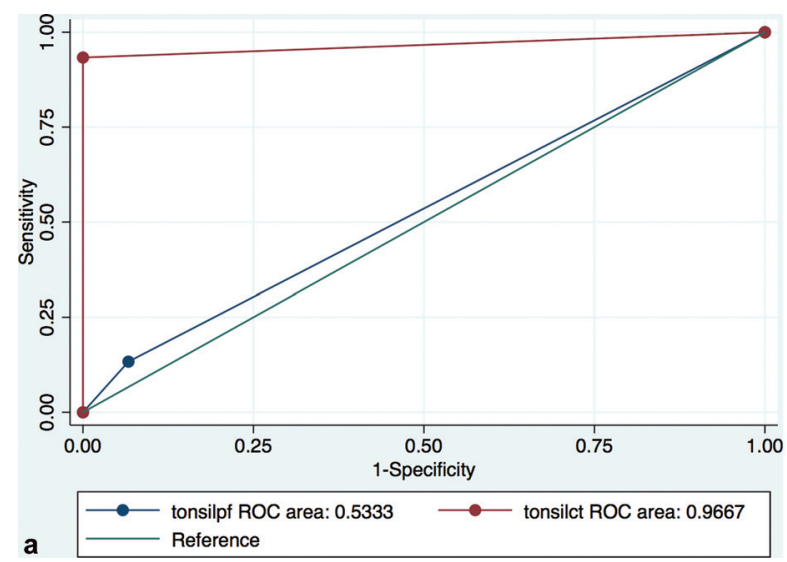

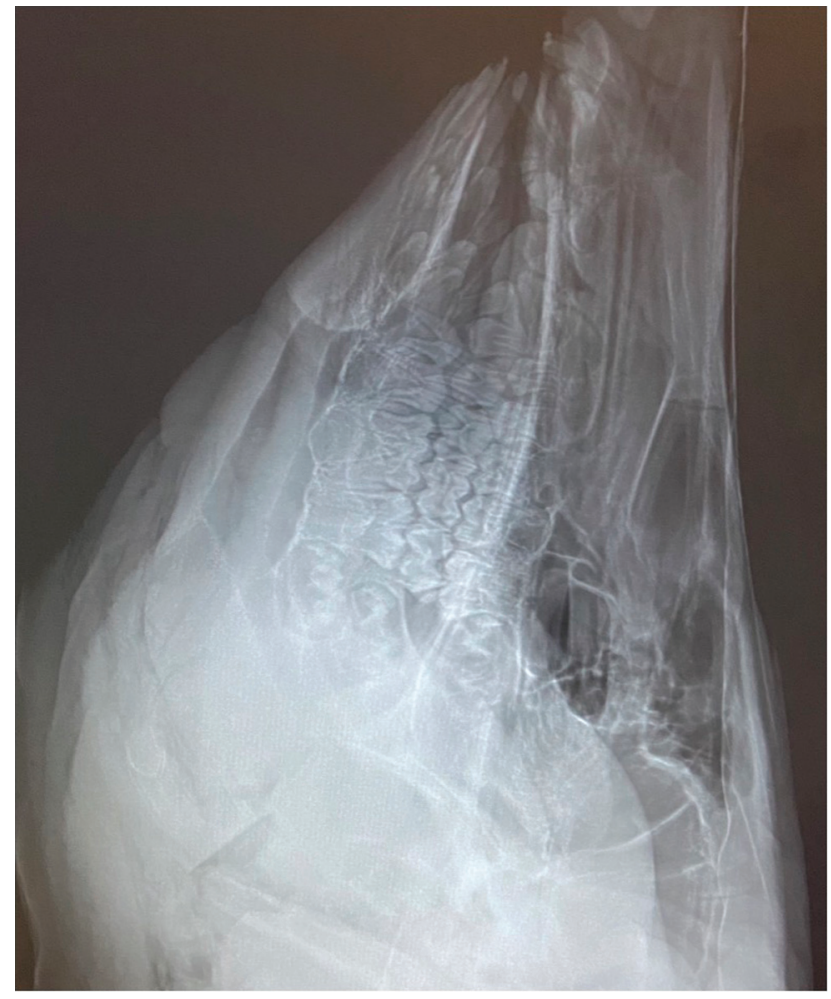

Fig. 4 Tongue sole bone embedded at tonsillar region which is not visualized by digital radiograph.

because it is well known that bony structures can be seen with radiographs. However, unlike most bony foreign bodies, fishbones are small and show variation in opacity. Most of the common fishbones in Southeast Asia, particularly in Thailand, cannot be not visualized by digital radiograph when embedded in the neck. The tonsillar region shows the lowest sensitivity in visualization of embedded fishbones, probably due to surrounding air and overlying bony structures (-Fig. 4). However, some particular fishbones with greater opacification, such as catfish bones (number 6 in - Fig. 1), can be visualized even in the tonsillar region (-Fig. 5).

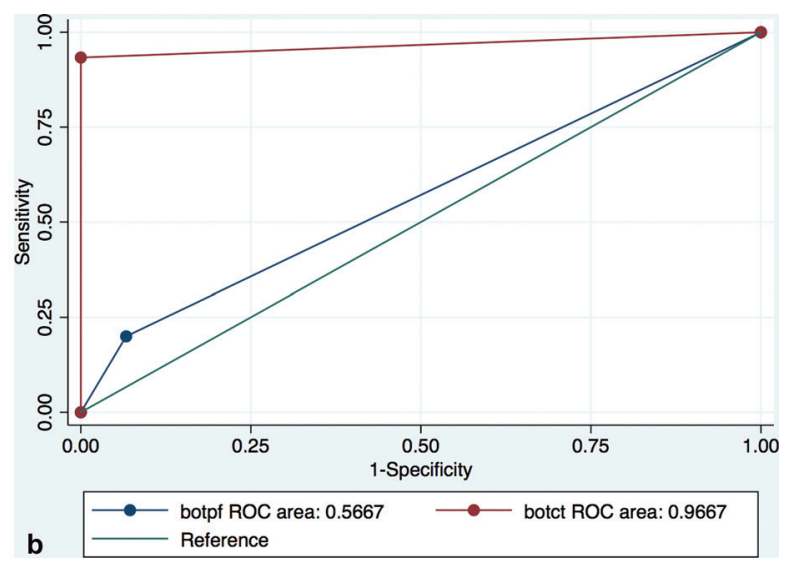

Fig. 3 A receiver operator characteristics curve for diagnostic performance of digital radiograph (blue line) compared with computed tomography images (redline) at tonsillar region. 3b Receiver operator characteristics curve for diagnostic performance of digital radiograph (blue line) compared with computed tomography images (red line) at base of tongue. $3 c$ Receiver operator characteristics curve for diagnostic performance of digital radiograph (blue line) compared with computed tomography images (red line) at upper esophagus. 


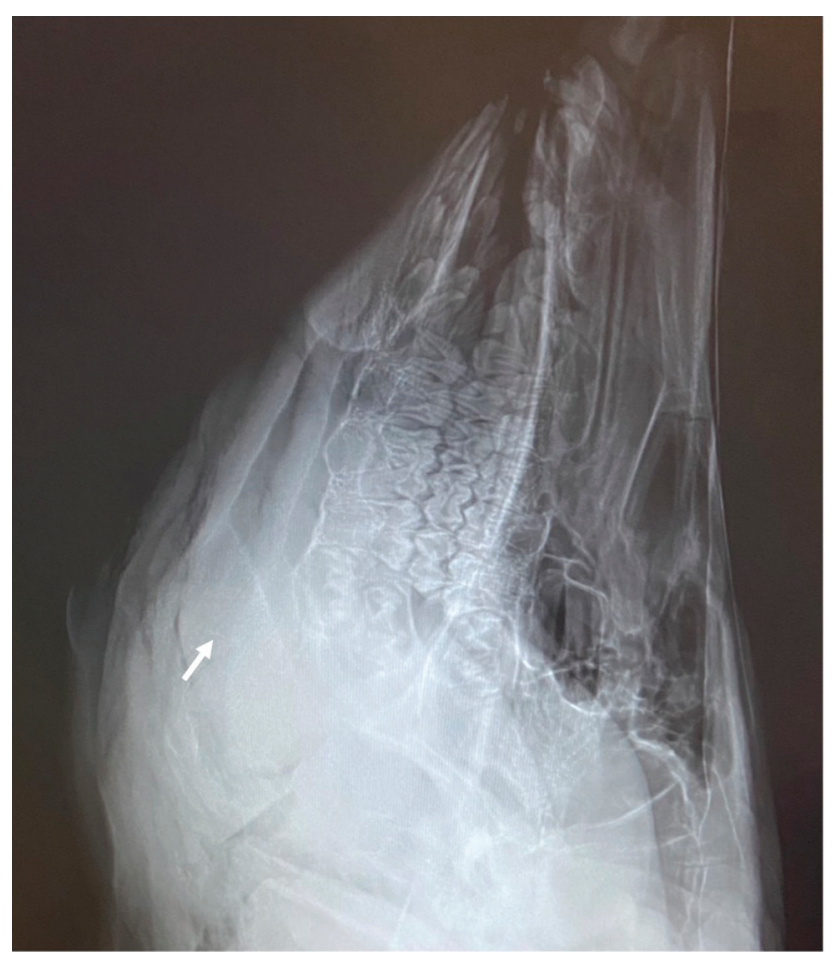

Fig. 5 Catfishbone embedded at tonsillar region, visible by digital radiograph (arrow).

Overlying bony structures or surrounding air do not affect the visibility of fishbones in CT scan, differently from digital radiograph. Therefore, the locations of the embedded fishbone were accurately identified (-Fig. 6). However, some fishbone species which do not or faintly opacified cannot be visualized by CT scan ( - Fig. 7), as demonstrated in - Figure 1 numbers 11 (Longtail tuna) and 12 (Silver pomfret). The

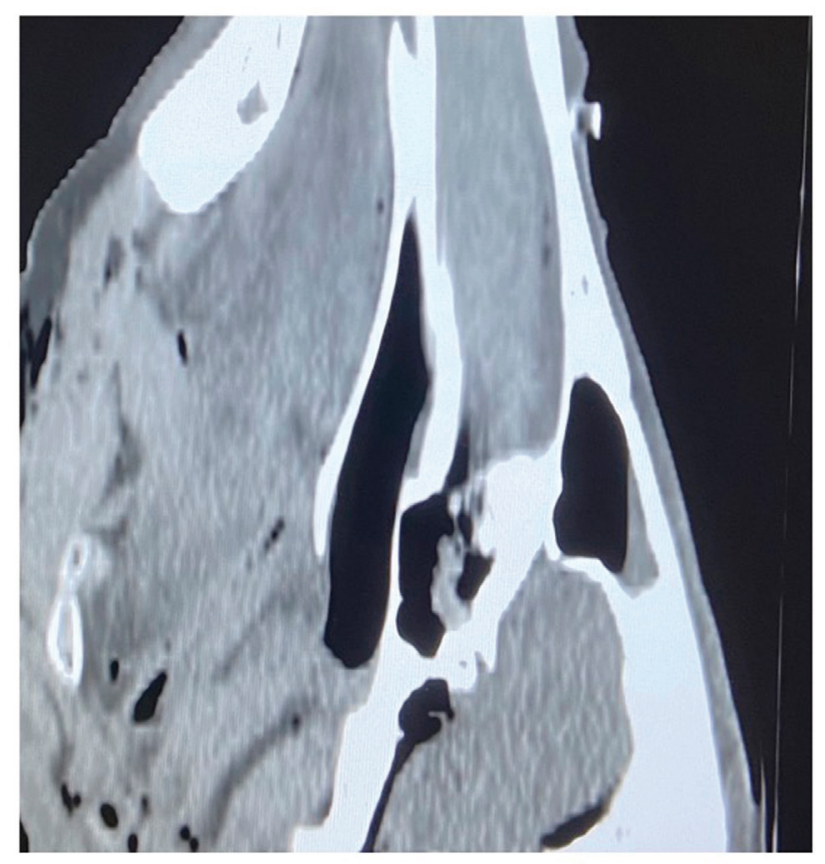

Fig. 7 Long tail tuna bone, not visualized by computed tomography.

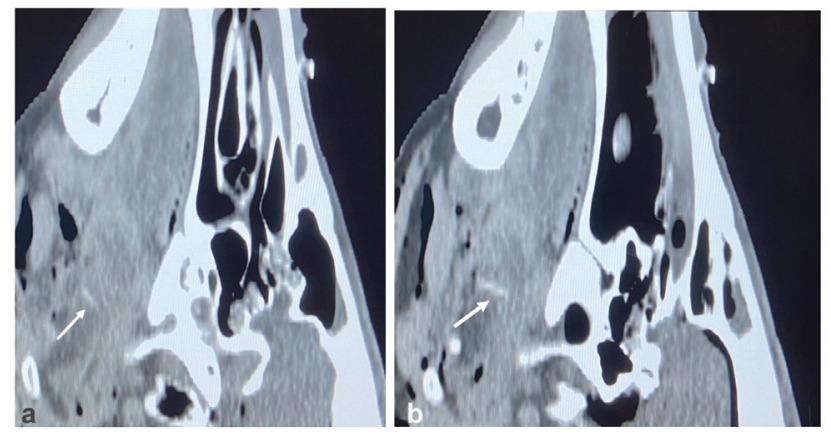

Fig. 6 6a Asian seabass bone embedded at tonsillar region, visualized by computed tomography (arrow). 6b Salmon bone at base of tongue, visualized by computed tomography (arrow).

bones of these species are thin and show subtle opacification even when not embedded in soft tissue.

With developing technology, we can reduce the radiation dosage while maintaining diagnostic performance. Nonetheless, the CT radiation dosage is still about 20 times higher than that of digital radiograph. Radiation dosage is one of the factors that influences the choice of imaging modalities.

\section{Conclusion}

Computed tomography scans demonstrate better diagnostic performance of fishbone retention compared to digital radiographs, regardless of the embedded location. However, despite the decreased radiation dosage from CT scans, the total dose per study is still 20 times higher than that of digital radiographs.

FundingSuranaree University of Technology.

\section{Conflict of Interests}

The authors have no conflict of interests to declare.

\section{References}

1 Kim HU. Oroesophageal fishbone foreign body. Clin Endosc 2016; 49(04):318-326

2 Klein A, Ovnat-Tamir S, Marom T, Gluck O, Rabinovics N, Shemesh S. Fishbone foreign body: the role of imaging. Int Arch Otorhinolaryngol 2019;23(01):110-115

3 Dray X, Cattan P. Foreign bodies and caustic lesions. Best Pract Res Clin Gastroenterol 2013;27(05):679-689

4 Venkatesh SH, Venkatanarasimha Karaddi NK. CT findings of accidental fishbone ingestion and its complications. Diagn Interv Radiol 2016;22(02):156-160

5 Kim JP, Kwon OJ, Shim HS, Kim RB, Kim JH, Woo SH. Analysis of clinical feature and management of fishbone ingestion of upper gastrointestinal tract. Clin Exp Otorhinolaryngol 2015;8(03):261-267

6 Chiu HS, Chung CH. Management of foreign bodies in throat: an emergency department's perspective. Hong Kong J Emerg Med 2002;9:126-130

7 Sanei-Moghaddam A, Sanei-Moghaddam A, Kahrobaei S. Lateral soft tissue $\mathrm{x}$-ray for patients with suspected fishbone in oropharynx, a thing in the past. Iran J Otorhinolaryngol 2015;27(83):459-462

8 Kasemsiri P, Mahawerawat K, Ratanaanekchai T, Puttarak W, Munkong W. The accuracy of digital radiography for diagnosis 
of fishbone foreign bodies in the throat. Int Arch Otorhinolaryngol 2017;21(03):255-258

9 Qureshi TA, Awan MS, Hussain M, Wasif M. Effectiveness of plain $\mathrm{X}$-ray in detection of fish and chicken bone foreign body in upper aerodigestive tract. J Pak Med Assoc 2017;67(04):544-547

10 Woo SH, Kim KH. Proposal for methods of diagnosis of fishbone foreign body in the Esophagus. Laryngoscope 2015;125(11): 2472-2475
11 Schmid AI, Uder M, Lell MM. Reaching for better image quality and lower radiation dose in head and neck CT: advanced modeled and sinogram-affirmed iterative reconstruction in combination with tube voltage adaptation. Dentomaxillofac Radiol 2017;46(01): 20160131. Doi: 10.1259/dmfr.20160131

12 Gao N, Cui X, Sun G, Zhang G, Zhou G, Zhao X. Comparative anatomy of pig arytenoid cartilage and human arytenoid cartilage. J Voice 2019;33(05):620-626. Doi: 10.1016/j.jvoice.2018.02.015 